\title{
Clinical and Subtypes of Breast Cancer in Indonesia
}

\author{
I Ketut Widiana, Hendry Irawan
}

Surgical Oncology Division, Department of Surgery, Medical Faculty Universitas Udayana, Sanglah General Hospital Denpasar, Bali, Indonesia.

\begin{abstract}
Background: Breast cancer is still a global public health problem, especially in women and is the second leading cause of death after lung cancer. Indonesia is a country with a high incidence of breast among women. Methods: This study used a retrospective study of breast cancer patients registered at Division of Surgical Oncology in Indonesia. Information about demographic, clinical and pathological characteristics of patients for a period of 5 years (2014 to 2020) were collected and described. Results: Information for 1260 cases of breast cancer who underwent IHC examination with an average age of 53.73 years of patients, with the most age above 50 years (63.6\%) were collected. On IHC examination, 58.6\% positive estrogen receptors were found, positive progesterone receptors were $55.4 \%$, Her2 was positive $37.7 \%$ and high Ki67 protein was $56.9 \%$. The most common breast cancer subtypes were luminal B (43.2\%), followed by luminal A (21.7\%), TNBC (18.1\%), and Her2 (17\%), with the highest stages being IIIB (31.7\%). Conclusions: The breast cancer was presented at higher stage, with more cases with estrogen or progesterone receptors are positive with low frequency of Her2 positivity and high in Ki67 protein expression.
\end{abstract}

Keywords: Breast cancer- Indonesia- immunohistochemistry- subtypes- staging

\section{Introduction}

Breast cancer is currently still a global public health problem. Specifically, in women, breast cancer is the second leading cause of death after lung cancer. The highest incidence of cancer types is diagnosed in women in the Southeast Asian region and in the world [1]. Indonesia is one of the countries with a high incidence of breast cancer then Japan, Malaysia, the Philippines, Singapore, Sri Lanka, and Taiwan [2]. Based on GLOBOCAN 2008, in Southeast Asia, Singapore ranks highest with the highest incidence of breast cancer at $59.9 \%$ per 100,000 population, while Indonesia is the country with the highest breast cancer mortality rate of around $18.6 \%$ per 100,000 population [1]. Breast cancer in Indonesia is the second highest number of cancer cases in women after cervical cancer [2-3].

In 2018 , breast cancer in women had an incidence of $11.6 \%$ and mortality of $6.6 \%$ of all cancers in men and women, while specifically in women, breast cancer had the highest incidence, which was $24.2 \%$ with a mortality of $15 \%$ [4]. Based on data from the International Agency for Research on Cancer (IARC), it is known that in 2012 the incidence of breast cancer in women in Indonesia was $43.3 \%$ and the percentage of deaths was $12.9 \%$ [5].

In the selection of therapy and predicting prognosis, immunohistochemical examination (IHC) becomes one of the mandatory examinations. IHC examination is a technique used to characterize intracellular proteins or cell surfaces in body tissues [6]. This examination is carried out as an initial step in determining the diagnosis, treatment and prognosis of breast cancer patients [6]. In IHC examination, subtypes of breast cancer cells have been identified using gene expression profile, is complex and relatively expensive. Cell subtypes are identified using biological markers which will then show the presence or absence of estrogen receptors (ER + / ER -), progesterone receptors (PR + / PR -), Human Epidermal Growth Factor Receptor 2 (HER2 + / HER2 -), and Ki67 proteins (low / high). This subtype of breast cancer cells is increasingly being developed as an initial step in the selection of therapy and predicting the prognosis of breast

\footnotetext{
Corresponding Author:

Dr. Hendry Irawan

Surgical Oncology Division, Department of Surgery, Medical Faculty Universitas Udayana, Sanglah General Hospital Denpasar, Bali, Indonesia.

Email: hendry_irawan@rocketmail.com.
} 
cancer patients [6-7].

On St. Gallen 2015, said that breast cancer was divided into four subtypes identified based on ER and PR excessive or nonexistent, Ki67 protein, and the presence of excessive amplification in HER oncogenes.6,8 Four known subtypes are luminal A, luminal B, positive HER2, and Basal-like are often found, namely Triple Negative Breast Cancer (TNBC) [8].

Luminal $\mathrm{A}$ is the most common subtype found in about $50-60 \%$ of all breast cancer subtypes. In luminal A there is an increase in ER and decreased proliferation of cancer related genes [6-7]. Breast cancer patients with luminal A subtypes have a better prognosis and have lower recurrence rates than other subtypes [7].

The luminal B subtype is found to be around 15$20 \%$ of all breast cancer subtypes and has a more aggressive phenotype, with a higher level of malignancy, a proliferation index, and a worse prognosis compared to luminal A [6-7]. This subtype has a higher recurrence rate and when it occurs this happens, the survival rate is lower than that of luminal A [7]. All breast cancer patients with luminal subtypes are given hormone therapy because they are considered to provide better results in therapy [7-9].

The positive HER2 subtype is found to be around $10-20 \%$ of the breast cancer subtype. Biologically or clinically positive HER2 is more aggressive and has a higher level of metastasis to the brain and lungs compared to the luminal subtype [7]. This subtype is characterized by increased expression of the HER2 gene and other genes associated with the HER2 pathway. The positive HER2 subtype has a poor prognosis [6-7-9].

Basal-like consists of many types. One type of Basal-like often found is TNBC. In the IHC classification, TNBC is a subtype not expressing ER, PR, and HER2. It should be explained that TNBC and Basal-like are not entirely the same, and there are about $20-30 \%$ discrepancies between studies [6-7]. As with positive HER2, patients with this subtype have a worse prognosis than patients with luminal subtypes. In the HER2 positive and Basal-like or TNBC subtypes, the recommended therapy is adjuvant-based chemotherapy [9]. In several studies saying that IHC examination can classify subtypes, genetic, and molecular characteristics are closely related and can help prognosis, tumor aggressiveness, and treatment selection in breast cancer patients [6-8-9].

\section{Materials and Methods}

This research uses a retrospective descriptive study. The research data was taken from patient data which was diagnosed with breast cancer and an immunohistochemical examination (IHC) was performed. Data collection was conducted from 2014 to 2019 and this data is secondary data obtained from breast cancer registration data in the Division of Surgical Oncology in Indonesia. The research sample was taken using a total sampling system. Inclusion criteria including all data on breast cancer patients have been carried out IHC examination in 2014-2019 accompanied by information in the form of age, stage of breast cancer, the main diagnosis of pathology. Exclusion criteria were patients with incomplete medical records. The data is then processed using the Windows version of the IBM Statistical Product and Service Solution (SPSS) v.23 program. This research was analyzed descriptively. Then the data will be summarized in the form of frequency distribution Table and Figure.

\section{Results}

Examination of IHC in breast cancer patients in Indonesia has become a routine procedure done. This is evident from the research data taken from the Division of Surgical Oncology, obtained cases of breast cancer in 2014-2019 IHC examination was carried out as many as 1260 cases. The average age of breast cancer was 53.73 years with a standard deviation of 9.89 and the youngest age for breast cancer was 25 years and the oldest age for breast cancer was 87 years. The distribution of the IHC results in Table 1 shows that, by age, the most prevalent events were found to be more than 50 years old, whereas

Table 1. Characteristics of Breast Cancer Patients

\begin{tabular}{|c|c|c|}
\hline Characteristics & $\mathrm{N}=1260$ & $\%$ \\
\hline \multicolumn{3}{|l|}{ Age } \\
\hline$<50$ years old & 459 & 36.4 \\
\hline$\geq 50$ years old & 801 & 63.6 \\
\hline \multicolumn{3}{|l|}{ Menstruation } \\
\hline Pre-menopause & 646 & 51.3 \\
\hline Menopause & 614 & 48.7 \\
\hline \multicolumn{3}{|l|}{ Tumor Size } \\
\hline $\mathrm{T} 1$ & 47 & 3.7 \\
\hline $\mathrm{T} 2$ & 345 & 27.4 \\
\hline $\mathrm{T} 3$ & 259 & 20.6 \\
\hline $\mathrm{T} 4$ & 609 & 48.3 \\
\hline \multicolumn{3}{|l|}{ Stage } \\
\hline I & 43 & 3.4 \\
\hline IIA & 202 & 16 \\
\hline IIB & 214 & 17 \\
\hline IIIA & 145 & 11.5 \\
\hline IIIB & 400 & 31.7 \\
\hline IV & 36 & 2.9 \\
\hline \multicolumn{3}{|l|}{ Estrogen Receptors } \\
\hline Negative & 522 & 41.4 \\
\hline Positive & 738 & 58.6 \\
\hline \multicolumn{3}{|c|}{ Progesterone Receptors } \\
\hline Negative & 562 & 44.6 \\
\hline Positive & 698 & 55.4 \\
\hline \multicolumn{3}{|l|}{ Her2 } \\
\hline Negative & 785 & 62.3 \\
\hline Positive & 475 & 37.7 \\
\hline \multicolumn{3}{|l|}{ Ki67 } \\
\hline Low & 543 & 43.1 \\
\hline High & 717 & 56.9 \\
\hline
\end{tabular}




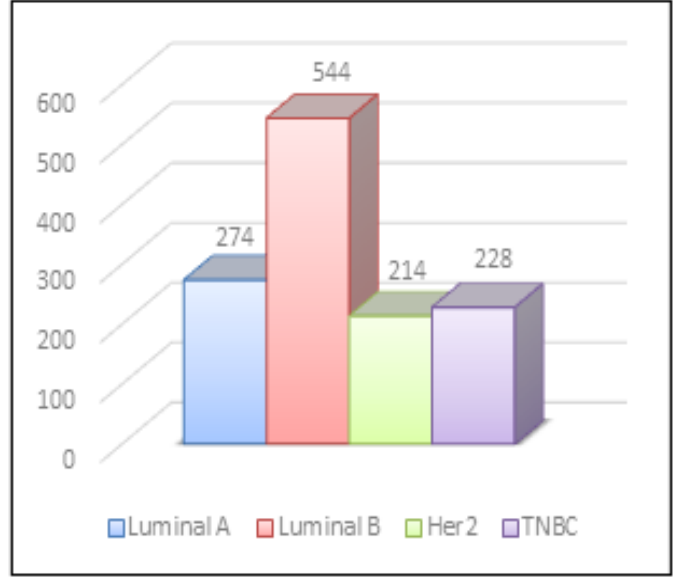

Figure 1. Distribution of Breast Cancer Subtypes

from the stage distribution most breast cancer sufferers were at stage IIIB.

The IHC results showed that the detection of hormone receptors in breast cancer patients was positive estrogen hormone receptors $(\mathrm{ER}+)$ in $738(58.6 \%)$ cases and positive progesterone hormone receptor $(\mathrm{PR}+)$ in 698 $(55.4 \%)$ cases. Examination of HER2 was found to have negative HER2 in $785(62.3 \%)$ cases. High Ki67 protein expression in 717 (56.9\%) cases.

\section{Breast cancer subtypes in Indonesia}

Based on the IHC examination, it is known that breast cancer subtypes in Indonesia such as luminal B subtypes (ER + / PR +, HER2 + or high Ki67) were found to be the most compared to other subtypes as many as $544(43.2 \%)$, positive HER2 subtypes (ER -, PR - , HER2 +) at least 214 (17\%), TNBC subtypes (ER -, PR -, HER2 -) were found 228 (18.1\%), and luminal A subtypes (ER + / PR +, HER2 -, low Ki67) as many 274 $(21.7 \%)$. The distribution of breast cancer subtypes can be seen more clearly in Figure 1. If we look based on the expression of HER2 in the luminal B subtype, we found that from $43.2 \%$ of the luminal B subtype, there were 283 $(22.5 \%)$ HER2 - and 261 (20.7\%) HER2 +.

\section{Discussion}

The IHC examination has been around since 2003, and the last two years have been carried out routinely in Indonesia. Examination of IHC used to be known as expensive examination, can now be done because it has been entered into one of the laboratory examinations covered by Indonesia government health insurance such as BPJS. This certainly will have an impact on the future for the development of therapy and assessment of prognosis for breast cancer patients.

Based on the IHC examination carried out as a whole, positive hormone receptor (luminal type) were the most cases found with the number 818 (64.9\%). Referring to European studies on European and Arab / Moroccan breast cancer cases with a total sample of 350 European ethnic cases and 91 ethnic Arab / Moroccan cases, the results showed not much different, luminal type was $86 \%$ and $79.12 \%$, respectively [10]. Similar results were found in other studies in Southeast Asia with a percentage of $63.6 \%$ and research in China with a percentage of $70.5 \%$ was luminal type [11-12]. Similar results were also found in a study with a sample of 346 cases in ethnic Asians in America. The study found that ethnic Korean and Filipino women had lower positive hormone receptors at around $58.9 \%$ and $70.6 \%$ compared to Chinese and Japanese ethnic women at $82.6 \%$ and $91.4 \%$. However, this shows that ethnicity Asia has a percentage of more than $50 \%$ for positive hormone receptors [13].

Based on this, differences in the value of these hormone receptors may be influenced by racial and ethnic factors in each region. Most races and ethnicities are said to tend to have more positive hormone receptors than negative hormone receptors. The number of samples is limited and different in each study area may also affect differences in research results [14].

Besides positive hormone receptors also play a role in the choice of therapy in breast cancer patients is the value of HER2. In this study it was found that the frequency was quite high in negative HER2 of 785 cases $(62.3 \%)$. This study shows negative HER2 results are more dominant. Other results were found in Brazil with a positive HER2 presentation of $49.07 \%$ [15]. These results resemble those of a study with 1,104 samples getting a higher negative HER 2 of $64.4 \%$ compared to positive HER2 in Southeast Asia [11]. Research in China also supports this research with negative HER2 of $61.4 \%$ [12].

Based on the above results, the examination of HER2 should receive attention together with the examination of hormone receptors. This is due to the selection of different therapies (personalize) and prognosis in cancer patients. Positive HER2 is associated with a poor prognosis and a tendency for metastases to occur in other organs, recurrence, and high mortality.

Examination of breast cancer subtypes in Indonesia is dominated by luminal A subtypes as much as $21.7 \%$ and luminal B as much as $43.2 \%$. In a study in Brazil also found more luminal subtypes than other subtypes with a percentage of luminal B subtypes as much as $44.61 \%$ greater than luminal $A$ as much as $23.79 \%$, while positive HER2 and Basal-like / TNBC were only found as much as $14.5 \%$ and $17.1 \%$ [15]. Other studies in China also found the same thing dominated by luminal B at 51.5\% [12]. Research in Yogyakarta found that the luminal A subtype was more prevalent with a percentage of $38.1 \%$ while luminal B was only $16.7 \%$ [14]. One study in Southeast Asia was also dominated by the luminal A subtype with $45.8 \%$ [11]. When observed, this study is almost the same as most studies stating that the luminal subtype is the most common subtype found in breast cancer patients compared with positive and Basal-like / TNBC subtypes in Indonesia.

Luminal subtypes have characteristics affecting hormone receptors on IHC examination. This subtype is the main predictive factor for hormone therapy. Luminal A is said to have a better prognosis than other subtypes. In contrast to luminal A, luminal B tends to have a worse 
prognosis, although treatment with hormone therapy is the same. This is due to the proliferation of cancer cells (Ki67 protein) is higher in luminal B compared to luminal A. In patients with positive HER2 subtypes and Basal-like / TNBC breast cancer both have a worse prognosis compared to luminal subtypes. In this subtype, the combination therapy is chosen as chemotherapy and targeted therapy.

Luminal is a subtype more often found in old age, while Basal-like / TNBC and HER2 positive subtypes are more frequent at a young age [14]. Based on the statement, research results obtained in Indonesia found similar things, where luminal subtypes were found most often in patients over the age than 50 years, while the Basal-like / TNBC subtype was found more in patients aged less than 50 years. In the positive HER2 subtype, it was found the same number of cases between patients aged over 50 years or less than 50 years.

Ki67 protein shows the proliferation index of cancer cells expressed in all phases of the cell cycle except G0. The presence of a high Ki67 protein indicates a poor prognosis [16]. At the meeting of St. Gallen 2011, low proliferation was defined with a Ki67 index of less than 14\% [17], whereas at the St. Gallen 2013, decided the high proliferation limit was more than or equal to $20 \%$ [18]. In the study of Bustreo et al, the disease-free interval (DFI) and disease-specific survival (DSS) did not differ significantly between Ki67 [14] and 20\%. However, patients with Ki67 more than $20 \%$ show a worse prognosis [16].

Most breast cancer patients recorded in Indonesia are in stage IIIB and followed by stage IIB. The incidence of breast cancer in developed countries, especially the United States, can reach twice that of Asian countries, and the majority occurs at an early stage. This might be due to the lack of an early detection program and also the community still lacking information about this problem. Research in Yogyakarta found that breast cancer subtypes have a significant relationship between age and clinicopathological characteristics such as staging and histopathological grading of breast cancer [14].

This study still does not describe the overall population of breast cancer patients in Indonesia in 2014-2019. This is because the data obtained is only sourced from the data of patients coming and examining in Indonesia. Other breast cancer patients may come to other hospitals or not seek medical help so they are not recorded in this study.

In Conclusions, examination of IHC in breast cancer patients in Indonesia in 2014-2019 has recorded as many as 1260 cases. In the age category, the four subtypes were found mostly at the age of more than 50 years and most breast cancer sufferers recorded in Indonesia were in stage IIIB. On IHC examination, more cases with estrogen or progesterone receptors are positive, Her2 tests are mostly negative, and Ki67 protein is mostly high. Luminal B subtype was found the most compared to other subtypes.

\section{Acknowledgements}

Authors would like to thank all member of the Indonesian Society of Surgical Oncology who entry breast cancer patients data in the cancer registry.

\section{Conflict of Interest}

Authors declare no conflict of interest in this study.

\section{Funding}

None.

\section{References}

1. Kimman M, Norman R, Jan S, Kingston D, Woodward M. The Burden of Cancer in Member Countries of the Association of Southeast Asian Nations (ASEAN). Asian Pacific Journal of Cancer Prevention. 201202 29;13(2):411-420. https:// doi.org/10.7314/apjcp.2012.13.2.411

2. McDonald M, Hertz R, Lowenthal S. The Burden of Cancer in Asia. USA: Pfizer Medical Division; 2008..

3. Youlden DR, Cramb SM, Dunn NA, Muller JM, Pyke CM, Baade PD. The descriptive epidemiology of female breast cancer: An international comparison of screening, incidence, survival and mortality. Cancer Epidemiology. 2012 06;36(3):237-248. https://doi.org/10.1016/j. canep.2012.02.007

4. Bray F, Ferlay J, Soerjomataram I, Siegel RL, Torre LA, Jemal A. Global cancer statistics 2018: GLOBOCAN estimates of incidence and mortality worldwide for 36 cancers in 185 countries. CA: A Cancer Journal for Clinicians. 2018 09 12;68(6):394-424. https://doi.org/10.3322/caac.21492

5. Primadi O, Budijanto D, Kurniasih N, et al. Buletin Jendela Data dan Informasi Kesehatan. Jakarta: Bakti Husada Kementrian Kesehatan RI. 2015;.

6. Zaha DC. Significance of immunohistochemistry in breast cancer. World Journal of Clinical Oncology. 2014;5(3):382. https://doi.org/10.5306/wjco.v5.i3.382

7. Yersal O. Biological subtypes of breast cancer: Prognostic and therapeutic implications. World Journal of Clinical Oncology. 2014;5(3):412. https://doi.org/10.5306/wjco. v5.i3.412

8. Coates A, Winer E, Goldhirsch A, Gelber R, Gnant M, Piccart-Gebhart M, Thürlimann B, Senn H, André F, Baselga J, Bergh J, Bonnefoi H, Burstein H, Cardoso F, Castiglione-Gertsch M, Coates AS, Colleoni M, Curigliano G, Davidson NE, Di Leo A, Ejlertsen B, Forbes JF, Galimberti V, Gelber RD, Gnant M, Goldhirsch A, Goodwin P, Harbeck N, Hayes DF, Huober J, Hudis CA, Ingle JN, Jassem J, Jiang Z, Karlsson P, Morrow M, Orecchia R, Kent Osborne C, Partridge AH, de la Peña L, Piccart-Gebhart MJ, Pritchard KI, Rutgers EJ, Sedlmayer F, Semiglazov V, Shao Z, Smith I, Thürlimann B, Toi M, Tutt A, Viale G, von Minckwitz G, Watanabe T, Whelan T, Winer EP, Xu B. Tailoring therapies - improving the management of early breast cancer: St Gallen International Expert Consensus on the Primary Therapy of Early Breast Cancer 2015. Annals of Oncology. 2015 08;26(8):1533-1546. https://doi. org/10.1093/annonc/mdv221

9. Phipps A, Li C. Breast Cancer Biology and Clinical Characteristics. In: Li C, editor. Breast Cancer Epidemiology. New York: Springer-Verlag. 2010;:21-46.

10. Preat F, Simon P, Noel J. Differences in breast carcinoma immunohistochemical subtypes between immigrant Arab and European women. Diagnostic Pathology. 2014;9(1):26. 
https://doi.org/10.1186/1746-1596-9-26

11. Hashmi AA, Edhi MM, Naqvi H, Khurshid A, Faridi N. Molecular Subtypes of Breast Cancer in South Asian Population by Immunohistochemical Profile and Her2neu Gene Amplification by FISH Technique: Association with other Clinicopathologic Parameters. The Breast Journal. 201409 13;20(6):578-585. https://doi.org/10.1111/tbj.12329

12. Si W, Li Y, Han Y, Zhang F, Wang Y, Li Y, Linghu RX, Zhang $\mathrm{X}$, Yang J. Epidemiological and Clinicopathological Trends of Breast Cancer in Chinese Patients During 1993 to 2013. Medicine. 2015 07;94(26):e820. https://doi.org/10.1097/ md.0000000000000820

13. Chuang E, Christos P, Flam A, McCarville K, Forst M, Shin S, Vahdat L, Swistel A, Simmons R, Osborne M, Moore A, Mazumdar M, Klein P. Breast Cancer Subtypes in AsianAmericans Differ According to Asian Ethnic Group. Journal of Immigrant and Minority Health. 201201 28;14(5):754758. https://doi.org/10.1007/s10903-012-9577-7

14. Widodo I, Dwianingsih EK, Triningsih E, Utoro T, Soeripto S. Clinicopathological Features of Indonesian Breast Cancers with Different Molecular Subtypes. Asian Pacific Journal of Cancer Prevention. 201408 15;15(15):6109-6113. https://doi.org/10.7314/apjcp.2014.15.15.6109

15. de Macêdo Andrade AC, Ferreira Júnior CA, Dantas Guimarães B, Pessoa Barros AW, Sarmento de Almeida G, Weller M. Molecular breast cancer subtypes and therapies in a public hospital of Northeastern Brazil. BMC Women's Health. 201409 12;14(1). https://doi.org/10.1186/14726874-14-110

16. Bustreo S, Osella-Abate S, Cassoni P, Donadio M, Airoldi M, Pedani F, Papotti M, Sapino A, Castellano I. Optimal Ki67 cut-off for luminal breast cancer prognostic evaluation: a large case series study with a long-term follow-up. Breast Cancer Research and Treatment. 201605 07;157(2):363-371. https://doi.org/10.1007/s10549-016-3817-9

17. Goldhirsch A, Wood W, Coates A, Gelber R, Thürlimann B, Senn H. Strategies for subtypes - dealing with the diversity of breast cancer: highlights of the St Gallen International Expert Consensus on the Primary Therapy of Early Breast Cancer 2011. Annals of Oncology. 2011 08;22(8):17361747. https://doi.org/10.1093/annonc/mdr304

18. Untch* M, Gerber B, Harbeck N, Jackisch C, Marschner N, Möbus V, von Minckwitz G, Loibl* S, Beckmann MW, Blohmer J, Costa S, Decker T, Diel I, Dimpfl T, Eiermann W, Fehm T, Friese K, Jänicke F, Janni W, Jonat W, Kiechle M, Köhler U, Lück H, Maass N, Possinger K, Rody A, Scharl A, Schneeweiss A, Thomssen C, Wallwiener D, Welt A. 13th St. Gallen International Breast Cancer Conference 2013: Primary Therapy of Early Breast Cancer Evidence, Controversies, Consensus - Opinion of a German Team of Experts (Zurich 2013). Breast Care. 2013;8(3):1-1. https:// doi.org/10.1159/000351692

\section{c) (i) (8)}

This work is licensed under a Creative Commons AttributionNon Commercial 4.0 International License. 